\title{
A Rare Case of Masseter Muscle Cysticercosis in a Young Female Patient Managed Conservatively
}

\author{
Bhaumik Shah ${ }^{1}$, Hardik Dodia $^{2 *}$, Karnadev Solanki ${ }^{1}$
}

\begin{abstract}
Cysticercosis is caused by Taenia solium larvae infestation. Isolated oral cysticercosis is a very rare presentation of this disease. Here is a case of masseter cysticercosis in a young woman who presented with painful cheek swelling. Diagnosis is confirmed with history, clinical examination, and magnetic resonance imaging. Luckily patient got cured with conservative management.
\end{abstract}

Keywords: Albendazole, Cystercercosis, Masseter muscle cystercercosis, Masseter swelling

Asian Pac. J. Health Sci., (2020); DOI: 10.21276/apjhs.2020.7.3.4

\section{BACKGROUND}

Cysticercosis is caused by the larval stage of pork tapeworm, the cysticercus cellulosae. It results from the ingestion of tapeworm eggs through contaminated food and water or dirty hands. Hence, it is commonly associated with contaminated pork eating. The most frequent sites of cysticercosis are subcutaneous tissue, brain, muscles, heart, liver, lungs, and peritoneum. It is very common to find multiple sites involved in cysticercosis.

\section{Case Presentation}

A 28-year-old woman presented with swelling and pain on her right cheek for the past 6 months, she had on and off fever, difficulty opening mouth. Oral examination revealed tenderness near third molar on upper aspect and subsequent opposite cheek mucosa. Outer aspect showed swelling, hard tender mass was felt near angle of mandible. Bimanual palpation of the right masseter showed a tender, non-mobile nodule of approximately $1.5 \mathrm{~cm}$ diameter. Rest of the examination was within normal limits. There was no history of dryness of the mouth. She had history of consuming cooked meat at random place. She was on pain killers and did undergo some treatment for gum infection a year back.

\section{Investigations}

Magnetic resonance imaging (MRI) of masseter muscle showed an oval-shaped, well-encapsulated cyst of $1.3 \mathrm{~cm}$ diameter with ring enhancement and eccentric dot sign [Figure 1]. Lesion was lying just above trunk of facial nerve and did not compress it. This confirmed the diagnosis of cysticercosis.

\section{Management}

The patient was started on albendazole $400 \mathrm{mg}$ BD for 1 month and steroids for 1 month. The patient was evaluated after 1 month and to the surprise, swelling almost disappeared. The patient was relieved of pain and fever, mouth opening also increased. Repeat MRI scan showed cyst disappearance and fibrosis changes in masseter muscle. The patient was followed for 1 month with steroid tappering and the patient was doing fine with complete resolution of swelling and symptoms [Figure 2].
'Consultant ENT Surgeon, Ahmedabad, Gujarat, India

2Department of Plastic Surgery, Consultant Cosmetic Plastic Surgeon, Ahmedabad, Gujarat, India

Corresponding Author: Dr. Hardik Dodia, Department of Plastic Surgery, Consultant Cosmetic Plastic Surgeon, Ahmedabad, Gujarat, India.Email: hardikdodia008@gmail.com

How to cite this article: Shah B, Dodia H, Solanki K. A Rare Case of Masseter Muscle Cysticercosis in a Young Female Patient Managed Conservatively. Asian Pac. J. Health Sci., 2020; 7(3):15-17

Source of support: Nil

Conflict of interest: None

Received: 10/04/2020 Revised: 20/05/2020 Accepted:24/06/2020

\section{Discussion}

Cysticerci are spherical, milky white cysts containing a fluid, and a single invaginated scolex with hooklets. Cysticercosis can affect any part of the body, but most commonly the central nervous system which has the most serious outcome. ${ }^{[1,2]}$ Although the exact incidence is still unknown, oral cysticercosis is considered rare and a precise clinical diagnosis is not usually established. ${ }^{[3]}$ The most commonly involved intraoral sites are tongue (42.15\%), lips (26.15\%), and buccal mucosa (18.9\%). ${ }^{[4,5]}$ It is interesting to note that the involvement of masseter muscle is extremely rare. Reddy et al. ${ }^{[5]}$ and Mittal et al. ${ }^{[6]}$ reported similar cases of intramuscular cysticercosis in masseter muscle diagnosed by ultrasonography and were treated conservatively. Most of the patients presented with painless swelling, and solitary cheek swellings can present a diagnostic dilemma. Usually, the patient complains of swelling. Although pain is not a frequent feature, it had been reported in secondarily infected cases. ${ }^{[7]}$ Differential diagnosis of a solitary lesion in the masseter muscle includes inflammatory lesions of the parotid gland, neoplasms of accessory parotid gland, parotid gland obstruction, preauricular lymphadenopathy, primary and metastatic tumors of masseter muscle, sarcoidosis, intramuscular lipomas, and solitary neurogenic tumors such as neurilemmoma, neurofibroma, and vascular lesions such as hemangioma or lymphangioma.$^{[4,5]} \mathrm{A}$ study done by Chaurasia et al. ${ }^{[8]}$ showed that only a 3-day albendazole therapy is very effective to cure solitary cysticercus granuloma. ${ }^{[9]}$ Thus, when such a good response to a 3-day albendazole therapy has been documented in a previous 


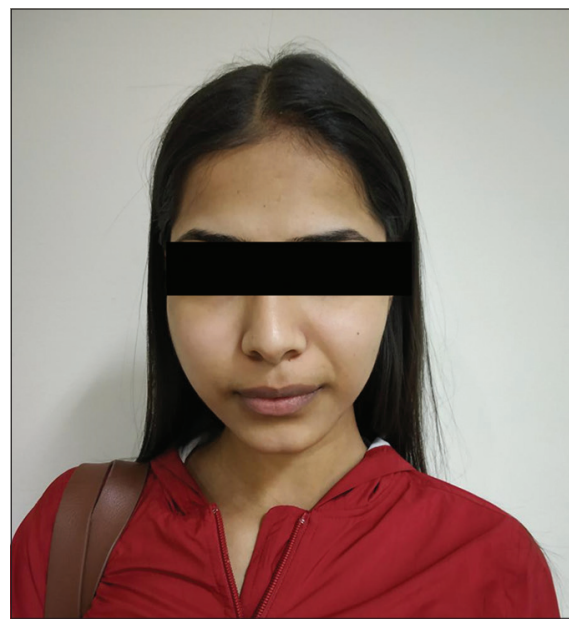

Figure 1: At presentation front profile

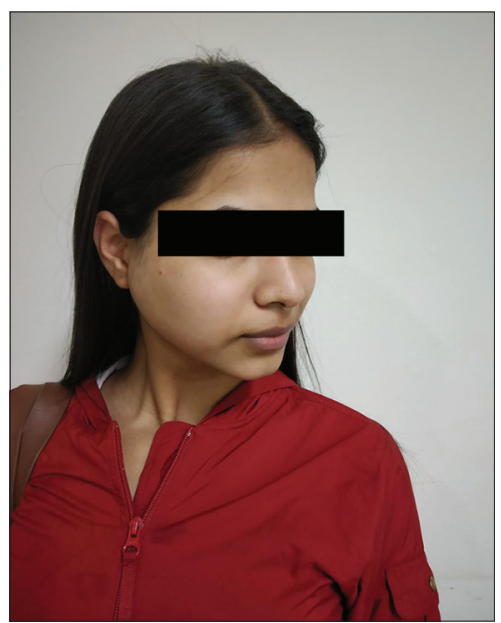

Figure 2: At presentation oblique presentation

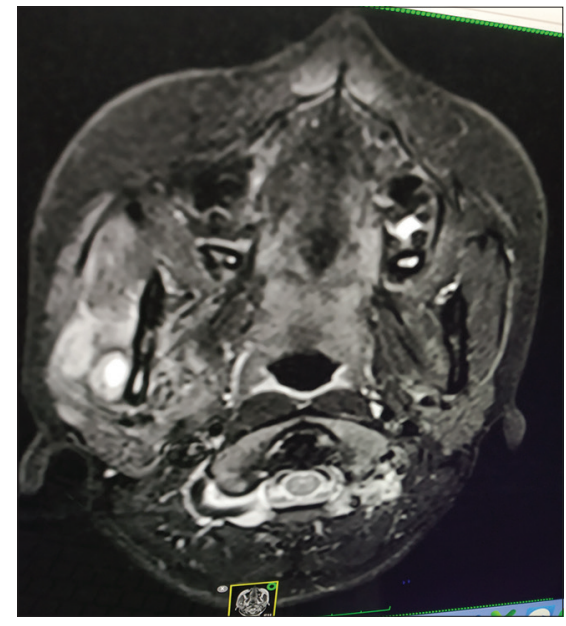

Figure 3: Pre-treatment computed tomography scan

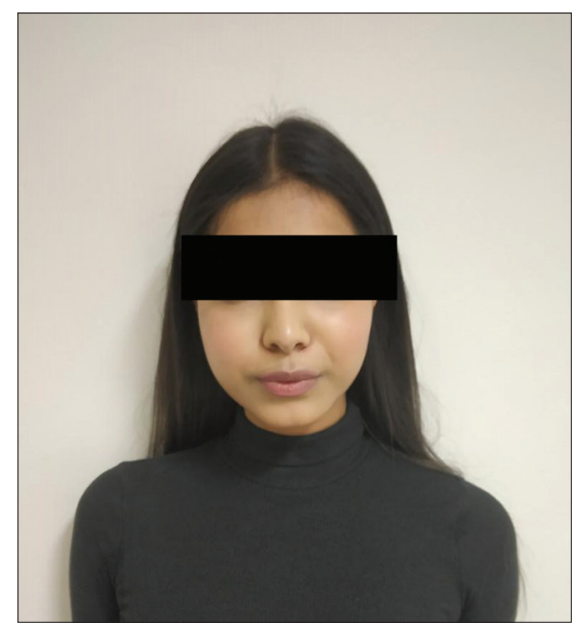

Figure 4: Post-treatment front picture

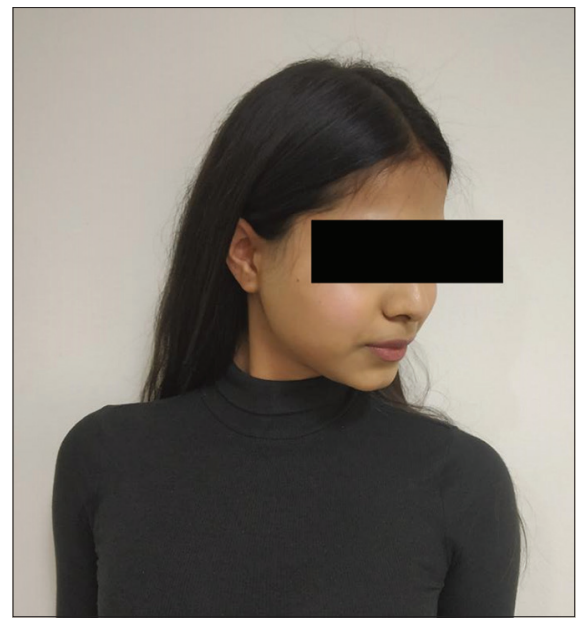

Figure 5: Post-treatment oblique profile

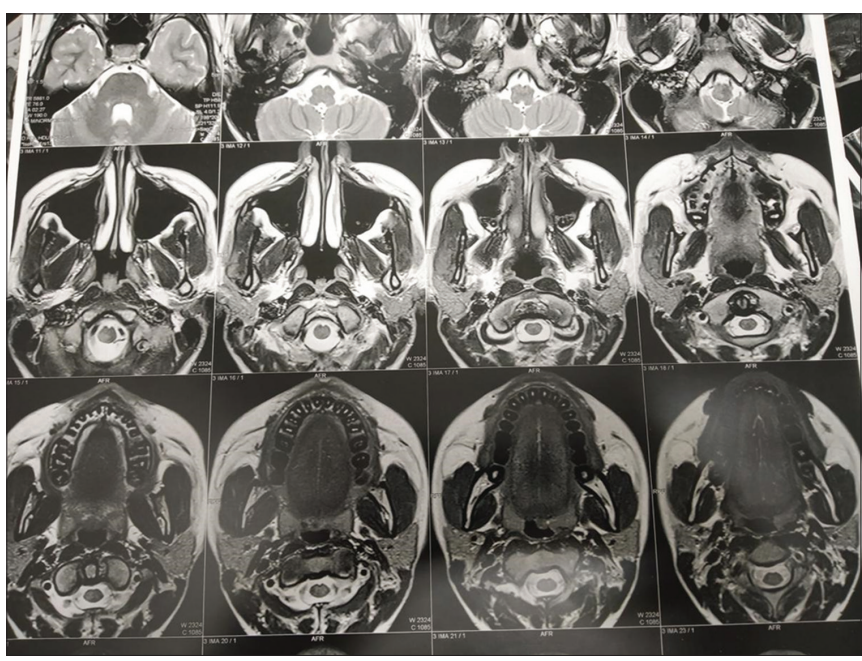

Figure 6: Post-treatment computed tomography scan 
study, this curable disease should be suspected when patients present with the aforementioned symptoms [Figures 3-6].

\section{Conclusion}

Diagnosis is confirmed with history, clinical examination, and magnetic resonance imaging. Luckily patient got cured with conservative management.

\section{References}

1. Flisser A, Plancarte A, Correa D, Rodriguez-Del-Rosal E, Feldman M, Sandoval $M$, et al. New approaches in the diagnosis of Taenia solium cysticercosis and taeniasis. Ann Parasit Hum Comp 1990;2013:95-8.

2. Wortman PD. Subcutaneous cysticercosis. J Am Acad Dermatol 1991;2013:409-14.
3. Pinswasdi P, Charoensiri DJ. Cysticercosis in labial tissue. Case report. Aust Dent J 1997;2013:319-21.

4. De Leon ER, Aguirre A. Oral cysticrcosis. Oral Surg Oral Med Oral Path Oral Radiol Endod 1995;2013:572-7.

5. Reddi SP, Molares MJ, Addante RD. Solitary lesion in the masseter muscle. J Oral Maxillofac Surg 2001;2013:71-5.

6. Mittal A, Das D, lyer N, Nagaraj J, Gupta M. Masseter cysticercosis-a rare case diagnosed on ultrasound. Dentomaxillofac Radiol 2008;2013:113-6.

7. Mishra YC, Nadkarni N. Oro-facial cysticercosis. Ann Dent 1988;2013:23.

8. Chaurasia RN, Garg RK, Agarwall A, Kohli N, Verma R, Singh MK, et al. Three day albendazole therapy in patients with a solitary cysticercus granuloma: A randomized double blind placebo controlled study. Southeast Asian J Trop Med Public Health 2010;2013:517-25.

9. Kumar BD, Dave B, Meghan SM. Cysticercosis of masseter. Year 2011;22:617. 